\title{
Northern European
}

National Cancer Institute

\section{Source}

National Cancer Institute. Northern European. NCI Thesaurus. Code C77814.

Denotes a person having origins in any of the countries of northern Europe such as

Belgium, Denmark, Austria, Switzerland, Norway, Sweden, or Great Britain. 